\title{
Cognitive Strategies, Motivation to Learning, Levels of Wellbeing and Risk of Drop-out: An Empirical Longitudinal Study for Qualifying Ongoing University Guidance Services
}

\author{
Valeria Biasi \\ Conny De Vincenzo \\ Nazarena Patrizi \\ Department of Education, \\ Roma Tre University, Roma, Italy
}

Doi: 10.2478/jesr-2018-0019

\begin{abstract}
The paper concerns a longitudinal empirical study aiming to establish the relation between certain factors that facilitate (or sometimes hinder) academic achievement such as motivation to study, the cognitive strategies employed and the levels of wellness or distress expressed by indicators like anxiety and depression. It thus aimed to identify the role of these factors on the risk of student drop-out. The study was carried out on a sample of 68 self-selected students enrolled in various degree courses at "Roma Tre" University, who had fully completed the three consecutive surveys geared to investigating their academic experience over a one-year period. The measurement tools used assessed: a) "drop-out intentions" (Hardre \& Reeve Scale, 2003); b) "wellness/distress levels", (Adult Self-Report ASR; Achenbach \& Rescorla, 2003); c) cognitive/study strategies (self-regulated knowledge; Manganelli, Alivernini, Mallia \& Biasi, 2015); d) motivational aspects (Academic Motivation Scale AMS, validated in Italy by Alivernini and Lucidi (2008). The results show how that the drop-out risk is linked to high levels of depression or distress, poor competence in cognitive strategies adopted, and high levels of "Amotivation" and "External Motivation". On the basis of the above empirical evidence we propose starting up specific ongoing actions within the university guidance services in order to simultaneously improve wellbeing through emotional support, redefine decisions in the study path in line with personal motivation, and develop adequate cognitive strategies to devise a functional study method.
\end{abstract}

Keywords: Anxiety, Cognitive strategies, Depression, Drop-out risk, Guidance, Motivation, Wellbeing

\section{Introduction}

It is unfortunate, as we know, that one of the critical features of the Italian university system is the high drop-out rate as highlighted in the relative survey on school drop-out (Indagine conoscitiva sulla Dispersione scolastica, Camera dei Deputati, 2014) and also confirmed by more recent data (Ballarino, 2011; Domenici, 2016, 2017; Burgalassi, Biasi, Capobianco \& Moretti, 2016). At the international level, the interpretations put forward to explain the phenomenon of drop-out risk, which is widespread in various countries, mainly point to the role of emotional and social factors (Pritchard \& Wilson, 2003; Murai \& Nakayama, 2008), as well as motivational factors, the capacity for selfregulation of knowledge and the levels of self-efficacy developed (Biasi, De Vincenzo \& Patrizi, 2017).

As we know, the psychological stress of university students is today an alarming problem on the rise and can considerably affect both personal development and health as well as academic 
performance (Hunt \& Eisenberg, 2010; Stallman, 2010; Storrie, Ahern, \& Tuckett, 2010; Geisner, Mallett, \& Kilmer, 2012; Ibrahim, Kelly, Adams, \& Glazebrook, 2013; Biasi, Patrizi, Mosca, \& De Vincenzo, 2016). In particular, depression and anxiety are widespread problems experienced by university students and can compromise academic and social functioning (Hysenbegasi, Hass, \& Rowland, 2005; Russell, \& Shaw, 2009; Farrer, Gulliver, Chan, Batterham, Reynolds, Calear, \& Griffiths, 2013; Davies, Morriss, \& Glazebrook, 2014; Bukhari \& Saba, 2017). A specific analysis of the literature carried out in 2013 by lbrahim, Kelly, Adams and Glazebrook, reported a mean rate of prevalence of depression of $30.6 \%$ in students. This review showed how depression among university students is associated to poor academic performance, instability in relations and suicidal thoughts and attempts. Many studies which have dealt with these issues from various perspectives have also investigated the role of variables such as self-regulation of knowledge in positively influencing student school or academic performance (Richardson, Abraham \& Bond, 2012; Diseth \& Kobbeltvedt, 2010; Heikkila et al., 2011) and in preventing university drop-out (De Marco \& Albanese, 2009). We are referring to Pintrich's self-regulated knowledge model (2004) according to which it is the cognitive and metacognitive strategies adopted by individuals which enable them to achieve their learning goals. These strategies lead to learning results in terms of knowledge, understanding and ability (Vermunt, 1998).

Starting from this construct, recent studies carried out by Biasi, De Vincenzo and Patrizi (2017) have made use of regression models to show the weight of certain factors predictive of university student drop-out risk. These include a condition of amotivation to the specific study undertaken, an inadequate mode of cognitive elaboration and poor perceived self-efficacy. The study also tried to investigate the role of important new variables expressing the level of wellbeing/distress (such as anxiety, depression and somatization) which, along with other motivational aspects and the cognitive strategies adopted by students, can have considerable influence in developing university drop-out risk. Bearing in mind that in the literature (Hysenbegasi, Hass \& Rowland, 2005; Russell \& Shaw, 2009; Stallman, 2010; Hunt \& Eisenberg 2010; Buchanan, 2012; Geisner, Mallett, \& Kilmer, 2012; Ibrahim, Kelly, Adams \& Glazebrook, 2013; Bukhari \& Saba 2017), anxiety, depression and abuse of hallucinatory substances negatively affect levels of wellbeing and have negative effects on academic performance, and considering - as said above that many studies indicate how important it is for students to adopt specific effective cognitive strategies to facilitate learning, we considered it important to develop an empirical procedure to test the mutual influence of these variables ("levels of wellbeing" - "typology of study motivation" "cognitive strategies adopted during the learning process") in favouring or inhibiting academic achievement.

As regards the relations between drop-out risk, the main cognitive strategies and study motivation, the relations already found in previous studies were effectively confirmed through the present study over the 12 months of its operation (Biasi, De Vincenzo \& Patrizi, 2017): the role of the indicated variables was thus established through confirmative analysis and their constant effect over time was also found.

With regard to motivational aspects, we also considered of particular importance the issue of motivation intrinsic to the type of study which gives substance to the university course chosen - an aspect which can be faced through adequate ongoing guidance interventions. In this regard, the effectiveness of motivational guidance interviews has already been experimentally demonstrated by Biasi, Patrizi, De Vincenzo \& Mosca (2017), both to promote the level of individual emotional wellbeing and to facilitate academic achievement of students who also face study delay which is also a drop-out risk factor. Within this experimental study, before and after the interview period, some questionnaires were administered to the participants, including the OQ-45 of Lambert and Hill (1994; Lo Coco, Chiappelli, Bensi, Gullo, Prestano, \& Lambert, 2008). The participants were divided into an experimental group (80 students who completed the first academic semester) and a control group (52 students put on a waiting list for the guidance session in the following semester). After describing the participants' characteristics (age, degree course attended, main areas of distress), their significant reduction of stress symptoms and other relational problems following the guidance sessions was highlighted. The data obtained confirmed the effectiveness and good stability of the effects of the intervention during the follow-up session. Compared to the control 
group, the students who followed the guidance process had a significant resumption of their studies. On the basis of these data, we can say that offering ongoing motivational and guidance services within the formal University Guidance Services can effectively be one of the many initiatives taken to facilitate academic achievement. These educational re-guidance processes could be made available to students requesting them and can operate alongside other kinds of didactic support - according to the student's needs - such as the offering of credit recovery courses as well as individualized online tutoring and/or didactic strategies.

\section{An Empirical Study Carried out at "Roma Tre" University}

\subsection{Aims, Methods, Procedure, Participants}

The present longitudinal study aimed to establish the relation between certain factors facilitating university students' academic achievement such as motivation to study, the cognitive strategies adopted and the levels of wellbeing or distress expressed by anxiety, depression and somatization indicators. The specific aim of this study thus consisted of identifying the role of these factors in influencing the risk of drop-out in order to devise preventive and/or coping strategies through specific ongoing university guidance services. To achieve these aims, on the basis of the theoretical framework and the research literature on the topic, a longitudinal study was carried out (with three consecutive surveys, the second two at 6- and 12-month intervals from the first). The responses given by 68 students were taken into examination. The students were enrolled in "Roma Tre" University's various degree courses and they agreed to take part in a broad online survey promoted by the University Counselling and Guidance Service. They completed the three consecutive surveys geared to assessing their academic experience over a year. The first survey was carried out between January and March 2015, the second between July and September 2015 and the third between November 2015 and January 2016. The mean age of the students involved was 22 years and 2 months ( $S D=5.76) ; 57.4 \%$ of the participants were female (39) and $42.6 \%$ were male (29). The mean age of the male students was 22 years and 8 months $(S D=6.11)$, while that of the female students was 21 years and 8 months $(S D=5.54)$. All 68 students were Italian.

Most of the participants $(88.2 \%)$ reported having gone to a scientific or humanistic high school, while $11.8 \%$ said they had attended a technical secondary school. The average grade obtained in the school-leaving examination was $84 / 100(S D=14.04) ; 72.1 \%$ of the students (49) were enrolled in an undergraduate degree course while $27.9 \%$ were enrolled in a master's degree course or in a five-year undergraduate program. Table 1 shows the details of the study's participants according to their degree courses, faculties or departments.

Table 1. Degree courses of the participating students: distribution of absolute and percentage frequencies

\begin{tabular}{lcc}
\hline & $\mathbf{F}$ & \% \\
\hline Engineering & 14 & 20.6 \\
Education & 13 & 19.1 \\
Languages & 8 & 11.8 \\
Humanities & 7 & 10.3 \\
Economics & 7 & 10.3 \\
Law & 6 & 8.9 \\
Political Science & 6 & 8.9 \\
Communication & 2 & 2.9 \\
Physics & 2 & 2.9 \\
Optics & 2 & 2.9 \\
Geology & 1 & 1.4 \\
\hline
\end{tabular}

In the first survey, $85.3 \%$ of the students reported being "on schedule" with their studies while $14.7 \%(10)$ said they were "behind schedule". On the other hand, in the third survey, $94.1 \%$ of the students were on schedule (64) while $5.9 \%$ (4) were behind schedule. The mean grade obtained in 
examinations by the whole sample of university students was 26.02 out of $30(S D=3.28)$. With regard to the number of hours dedicated to study, $44.1 \%$ of the participants reported devoting $3-4$ hours a day, $29.4 \%$ reported $5-6$ hours a day, $13.2 \%$ reported $1-2$ hours a day, $5.9 \%$ reported $7-8$ hours a day, $5.9 \%$ reported less than 1 hour a day, and $1.5 \%$ reported over 8 hours a day. With regard to lesson attendance, instead, $33.8 \%$ reported they had attended about $75 \%$ of their lessons, $32.4 \%$ reported attending about $100 \%$ of their lessons, $8.8 \%$ of the students reported $50 \%$ or $25 \%$ attendance, while $16.2 \%$ said they had not attended any lessons.

\subsection{Measurements}

As well as gathering data on the participants' demographics, cultural background and average grades in university examinations until then, the study also used some measurement tools to assess other constructs as follows:

\subsubsection{Intentions of dropping out}

The students' intentions with regard to continuing their education or dropping out of university were measured with items deriving from Hardre and Reeve's scale (2003). In the original version, the researchers took their cue from the version by Vallerand, Fortier and Guay (1997) to assess the students' intentions to continue or abandon their studies. In the present study, the students were asked the frequency with which they "think they have made a mistake in choosing their degree course", "think of quitting their degree course", "think of changing their degree course", "think of dropping-out of university to do something else". For each of the four items, the students' answers were evaluated on a 5-point Likert scale ranging from 1 (Never) to 5 (Always or nearly always) (cf. Biasi, De Vincenzo \& Patrizi, 2017). The Cronbach alpha coefficient was high (.79).

\subsubsection{Levels of wellbeing/distress assessed by means of the Adult Self Report (ASR) subscales}

Depression, anxiety and somatization symptoms were assessed by means of the DSM-oriented subscales of the Adult Self Report (Achenbach \& Rescorla, 2003) that focused on the problem behaviours experienced over the last month. The scale consists of the items of the Adult Self Report which researchers of various cultures have identified as in line with the DSM IV categories (Achenbach, Dumenci \& Rescorla, 2003) and previously employed in the Italian context (Lombardo, Mallia, Battagliese, Grano \& Violani, 2013). The ASR scales evaluate the presence of symptoms of depression or anxiety, somatic complaints, problems of avoidance personality, attention deficit/hyperactivity, and problems due to an antisocial personality. The present study considered the subscales concerning the presence of symptoms of anxiety, depression and somatization. The responses for each item were assessed on a 3-point scale: 0 ("Not true"), 1 ("A little or sometimes true") and 2 ("Very or often true"), with higher scores indicating a greater problem in these dimensions. Achenbach, Bernstein \& Dumenci (2005) demonstrated a good internal consistency for the subscales relating to depression symptoms $(\alpha=.79)$, anxiety symptoms $(\alpha=.71)$, somatic problems $(\alpha=.74)$, problems due to avoidance personality $(\alpha=.69)$, problems due to attention deficit or hyperactivity $(\alpha=.80)$ and problems due to an antisocial type personality $(\alpha=.76)$. Cronbach alpha reliability values were high: .89 for the "Depression" subscale, .72 for "Anxiety" and .75 for "Somatization".

\subsubsection{Cognitive/study strategies (Self-regulated knowledge) / "Self-Regulated Knowledge Scale - University" (SRKS-U)}

The cognitive strategies adopted were assessed by means of the Self-Regulated Knowledge Scale - University (SRKS-U) which was developed on the basis of Pintrich's theory of self-regulated knowledge and validated in Italy by Manganelli, Alivernini, Mallia and Biasi (2015). The scale was used to measure the frequency with which students implement different cognitive strategies and consists of a 5 -point scale $(1=$ Never; $2=$ Rarely; $3=$ Sometimes; $4=$ Often; $5=$ Always or nearly 
always). Its good psychometric properties were assessed in a recent study on a broad sample of Italian university students; Cronbach's alpha for the SRK subscale varied in this study from .80 (knowledge extraction) to .70 (knowledge monitoring) (Manganelli et al., 2015). The SRKS-U consists of five subscales, each composed of three items which answer the question "When studying, how often do you do the following?". The five subscales evaluate the use of the following cognitive processes: Knowledge Extraction (frequency with which students select information they consider more important); Knowledge Networking (frequency with which students try to connect new knowledge with what they already know); Knowledge Practice (frequency with which students implement their knowledge); Knowledge Critique (frequency with which students question themselves and criticize what they learn, gaining their own idea); Knowledge Monitoring (frequency with which students monitor their own knowledge). The scale initially consisted of 30 items, but only the 15 best items were later included in the final version of the scale. Cronbach's alpha was high: it was .76 for the Knowledge Practice subscale, .85 for Knowledge Extraction, .83 for Knowledge Critique, .82 for Knowledge Networking and .75 for Knowledge Monitoring.

\subsubsection{Motivation to study assessed through the "Academic Motivation Scale"}

Motivation to study was assessed by means of the Academic Motivation Scale developed within the Self-Determination Theory (Vallerand, Pelletier, Blais, Briere, Senecal, \& Vallieres, 1992, 1993) and validated in Italy by Alivernini and Lucidi (2008). The Italian version of the scale demonstrated good psychometric properties and Cronbach's alpha for the relative subscales ranges from .91 (External Regulation) to .73 (Amotivation). The scale consists of five subscales, each composed of four items which are answers to the question "Why are you attending the degree course you are enrolled in?" The five subscales assess: the lack of motivation indicated as "Amotivation": (typical answers include: "I honestly don't know" or "I feel I'm wasting my time in school"); External Regulation ("To get a more prestigious job later"); Introjected Regulation ("Because when I do well in school, I feel important"); Identified Regulation ("Because I think a high school education will help me to best prepare for the career path I have chosen"); Intrinsic Regulation ("Because I get pleasure and satisfaction from learning new things"). The choice of answers for each item are assessed on an 11-point scale ranging from 0 ("Not at all true") to 10 ("Completely true"). In this study, Cronbach's alpha ranged from .57 (Amotivation) to .91 (External Regulation).

\section{Results}

\subsection{Data Processing of the variables Anxiety, Depression, Somatization and Drop-out Risk}

Correlations were made to evaluate the relation between drop-out risk and the subscales concerning symptoms of anxiety, depression and somatization of the Adult Self Report for all three surveys. Table 2 shows that the first survey has a significant positive correlation between drop-out risk and anxiety $\left(r_{66}=.421 ; p<.001\right)$, between drop-out risk and depression $\left(r_{66}=.395 ; p<.001\right)$ and between depression and anxiety $\left(r_{66}=.742 ; p<.001\right)$. Hence, the greater the drop-out risk, the higher the scores for anxiety and depression obtained in the first survey. Moreover, higher anxiety scores are correlated with higher depression scores.

Table 2. Correlations between Drop-out Risk, Anxiety and Depression at time T1

\begin{tabular}{|c|c|c|c|c|c|c|}
\hline & & $\mathrm{T} 1$ & Drop-Out Risks & $\begin{array}{c}\text { T1 } \\
\text { Anxiety }\end{array}$ & $\begin{array}{c}\text { T1 } \\
\text { Depression }\end{array}$ & $\begin{array}{c}\mathrm{T} 1 \\
\text { Somatization }\end{array}$ \\
\hline T1 Drop-Out Risk & $\begin{array}{l}\text { Pearson's Correlation } \\
\text { Sig. (2- tailed) }\end{array}$ & & 1 & & & \\
\hline T1 Anxiety & $\begin{array}{l}\mathrm{N} \\
\text { Pearson's Correlation } \\
\text { Sig. (2- tailed) } \\
\text { N }\end{array}$ & & $\begin{array}{l}68 \\
.421^{\star *} \\
.000 \\
68\end{array}$ & 1 & & \\
\hline
\end{tabular}




$\begin{array}{ll}\text { T1 Depression } & \begin{array}{l}\text { Pearson's Correlation } \\ \end{array} \\ & \text { Sig. (2- tailed) } \\ \text { T1 Somatization } & \text { Pearson's Correlation } \\ & \text { Sig. (2- tailed) } \\ & N\end{array}$

$.395^{\star *}$
.001
68
.175
n.s.
68

\begin{tabular}{lc}
. $\mathbf{7 4 2}$ & 1 \\
.000 & \\
68 & \\
$.584^{* *}$ &. $\mathbf{5 8 5}^{\star *}$ \\
.000 & .000 \\
68 & 68 \\
\hline
\end{tabular}

The same relation can be found also in the second survey (Table 3 ). Thus, the greater the drop-out risk, the higher the scores for anxiety $\left(r_{66}=.287 ; p<.05\right)$ and depression $\left(r_{66}=.404 ; p<.001\right)$ obtained in the second survey.

Table 3. Correlations between Drop-out Risk, Anxiety and Depression at time T2

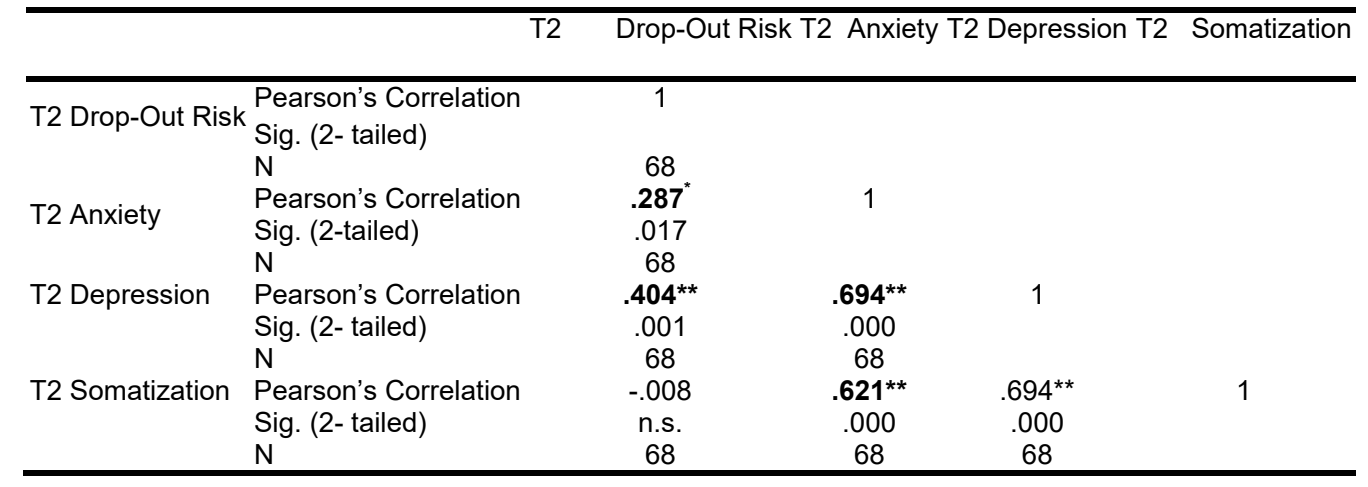

Instead, in the third survey the drop-out risk no longer correlates with anxiety scores, but continues to be associated with depression scores $\left(r_{66}=.495 ; p<.001\right)$ (Table 4). Hence, in the third survey, a greater drop-out risk is associated with greater depression symptoms.

Table 4. Correlations between Drop-out Risk, Anxiety and Depression at time T3

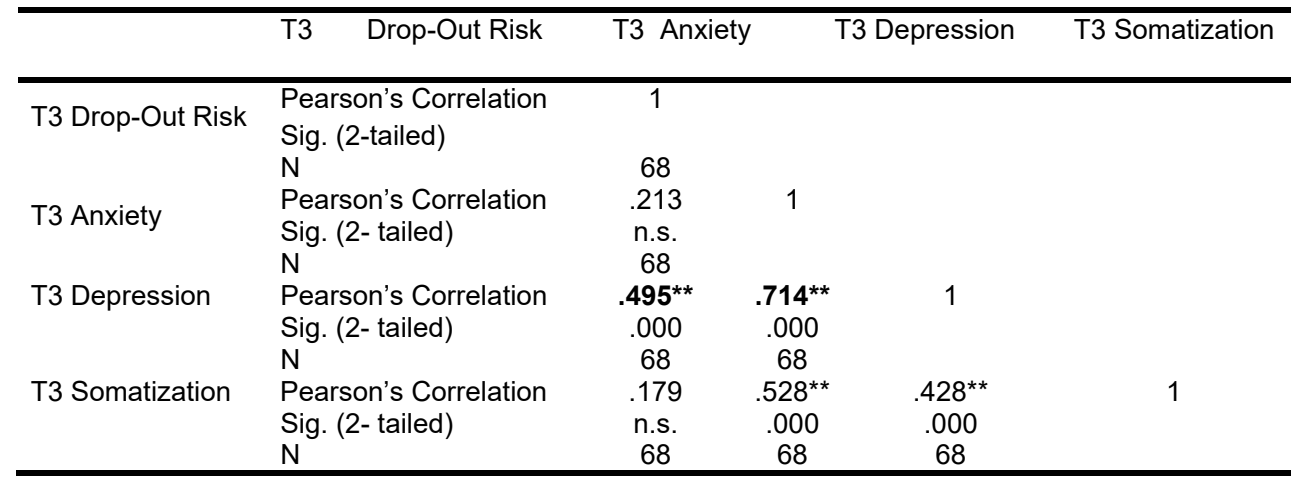

As regards somatization, no significant correlations were found with drop-out risk in the various times surveyed $\left(T 1: r_{66}=.175\right.$, n.s.; T2: $r_{66}=-.008$, n.s.; T3: $r_{66}=.179$, n.s.). However, somatization correlated positively in the various times with anxiety $\left(T 1: r_{66}=.584, p<.001\right.$; $T 2: r_{66}=.621, p<$ .001.; T3: $r_{66}=.528, p<.001$.) and with depression $\left(T 1: r_{66}=.585, p<.001\right.$.; T2: $r_{66}=.694, p<$ .001 ;; T3: $r_{66}=.428, p<.001$.). 
In summary, the results showed how a greater drop-out risk initially correlated significantly with higher anxiety and depression scores. In the third survey, conducted one year later, the drop-out risk strictly correlated only with depression, as the most important variable.

Some repeated measure ANOVAS were carried out to compare the scores obtained by the 68 participants in the various dimensions of the Adult Self-Report (anxiety, depression and somatization) across the three different surveys. In this regard, we noted a statistically significant effect for "Anxiety" in the three surveys $\left(F_{2,134}=3.372 ; p<.05\right)$ in the sense of a progressive decrease of anxiety scores obtained in the first survey $(M=13.69 D S=2.74)$ compared to those obtained in the third survey (M=12.98 DS= 2.63) (cf. Table 5).

Table 5. Means and Standard Deviations for the "Anxiety" variable in the three surveys

\begin{tabular}{cccc}
\hline & Mean & Standard Deviation & $\mathrm{N}$ \\
\hline Anxiety T1 & $\mathbf{1 3 . 6 9}$ & 2.74 & 68 \\
Anxiety T2 & 13.45 & 2.94 & 68 \\
Anxiety T3 & $\mathbf{1 2 . 9 8}$ & 2.63 & 68 \\
\hline
\end{tabular}

As regards scores for "Somatization", there was no statistically significant difference across the three surveys $(\mathrm{T} 1=13.16$; $\mathrm{T} 2=13.07$; $\mathrm{T} 3=12.96 \mathrm{~F}=.246$, n.s.; cf. Table 6).

Table 6. Means and Standard Deviations for the "Somatization" variable in the three surveys

\begin{tabular}{cccc}
\hline & Mean & Standard Deviation & $\mathrm{N}$ \\
\hline Somatization T1 & 13.16 & 2.98 & 68 \\
Somatization T2 & 13.07 & 2.76 & 68 \\
Somatization T3 & 12.96 & 2.64 & 68 \\
\hline
\end{tabular}

Even with regard to scores for depression, there was no statistically significant difference across the three surveys $(\mathrm{T} 1=20.78 ; \mathrm{T} 2=21.12 ; \mathrm{T} 3=21 ; \mathrm{F}=.288$, n.s.; cf. Table 7$)$.

Table 7. Means and Standard Deviations for the "Depression" variable in the three surveys

\begin{tabular}{cccc}
\hline & Mean & Standard Deviation & $\mathrm{N}$ \\
\hline Depression T1 & 20.78 & 5.69 & 68 \\
Depression T2 & 21.12 & 6.57 & 68 \\
Depression T3 & 21.00 & 5.79 & 68 \\
\hline
\end{tabular}

In short, drop-out risk, as shown above, appears significantly correlated especially to high and constant levels of depression, which are - as we know - an important form of distress or harmful stress with negative effects on performance, including academic performance.

With regard to anxiety, instead, as illustrated above, it appeared significantly correlated at the start of the surveys, but it did not remain constant across the three surveys. Hence, it carries less weight over time in co-determining drop-out risk.

\subsection{Data processing concerning the variables of Cognitive Strategies, Motivation to study and Drop-out risk}

Correlations were made to assess the relation between drop-out risk and cognitive strategies used by students and drop-out risk and motivation to study for all three consecutive surveys. As regards, cognitive strategies, table 8 shows that at time T1 there was no statistically significant relation with drop-out risk. 
Table 8. Correlations between drop-out risk and cognitive strategies at time T1

\begin{tabular}{|c|c|c|}
\hline \multirow{2}{*}{ Cognitive Strategies } & & T1 Drop-Out \\
\hline & Pearson's Correlation & -.160 \\
\hline II Extraction & Sig. (2- tailed) & n.s. \\
\hline T1 Critique & $\begin{array}{l}\text { Pearson's } \\
\text { Correlation }\end{array}$ & .160 \\
\hline & Sig. (2-tailed) & n.s. \\
\hline T1 Practice & $\begin{array}{l}\text { Pearson's } \\
\text { Correlation }\end{array}$ & -.115 \\
\hline & Sig. (2- tailed) & n.s. \\
\hline T1 Networking & $\begin{array}{l}\text { Pearson's } \\
\text { Correlation }\end{array}$ & -.58 \\
\hline & Sig. (2- tailed) & n.s. \\
\hline T1 Monitoring & $\begin{array}{l}\text { Pearson's } \\
\text { Correlation }\end{array}$ & -.184 \\
\hline & Sig. (2- tailed) & n.s. \\
\hline
\end{tabular}

At time T2 (cf. Table 9) there was a statistically significant negative correlation between drop-out risk and Knowledge Practice $\left(r_{66}=-.367 ; p<.001\right)$ and between drop-out risk and Knowledge Monitoring $\left(r_{66}=-.275 ; p<.05\right)$. Hence, the greater the drop-out risk, the lower the students' scores for Cognitive Strategies with regard to Knowledge Practice and Knowledge Monitoring.

Table 9. Correlations between drop-out risk and cognitive strategies at time T2

\begin{tabular}{llc}
\hline Cognitive Strategies & & T2 Drop-Out \\
\hline T2 Extraction & Pearson's Correlation & -.119 \\
T2 Critique & Sig. (2- tailed) & n.s. \\
& Pearson's Correlation & .017 \\
T2 Practice & Sig. (2- tailed) & n.s. \\
& Pearson's Correlation & $-.367^{* *}$ \\
T2 Networking & Sig. (2- tailed) & .002 \\
& Pearson's Correlation & -.158 \\
T2 Monitoring & Sig. (2- tailed) & n.s. \\
& Pearson's Correlation & $\mathbf{- . 2 7 5}$ \\
& Sig. (2- tailed) & .023 \\
\hline
\end{tabular}

Even in the third survey (cf. Table 10) there was a statistically significant negative correlation between drop-out risk and Knowledge Practice $\left(r_{66}=-.375 ; p<.001\right)$ and between drop-out risk and Knowledge Monitoring $\left(r_{66}=-.278 ; p<.05\right)$. Thus, the greater the drop-out risk, the lower the scores obtained for Cognitive Strategies with regard to Knowledge Practice and Knowledge Monitoring.

Table 10. Correlations between drop-out risk and cognitive strategies at time T3

\begin{tabular}{llc}
\hline Cognitive Strategies & & T3 Drop-Out \\
\hline T3 Extraction & Pearson's Correlation & -.191 \\
T3 Critique & Sig. (2-tailed) & n.s. \\
& Pearson's Correlation & -.012 \\
T3 Practice & Sig. (2-tailed) & n.s. \\
& Pearson's Correlation & $-.375^{\star *}$ \\
T3 Networking & Sig. (2-tailed) & .002 \\
& Pearson's Correlation & -.169 \\
& Sig. (2-tailed) & n.s. \\
& Pearson's Correlation & $-.278^{*}$ \\
& Sig. (2-tailed) & .022 \\
\hline
\end{tabular}


In sum, the greater the drop-out risk, the lower the scores obtained for Cognitive Strategies with regard to Knowledge Practice and Knowledge Monitoring across the two last surveys (i.e. at time T2 and T3). This means that these students do not functionally use the various cognitive strategies during the learning process and need to develop these very skills concerning self-regulated knowledge.

With regard to motivation to study, we can see that at time T1 (cf. Table 11) there is a positive correlation between drop-out risk and Amotivation $\left(r_{66}=.353 ; p<.001\right)$, between drop-out risk and External Motivation $\left(r_{66}=.270 ; p<.05\right)$, and between drop-out risk and Introjected Motivation $\left(r_{66}=\right.$ $.246 ; p<.05)$. Hence, a greater drop-out risk is correlated in particular with greater Amotivation scores as well as greater levels of External Motivation and Introjected Motivation.

Table 11. Correlations between drop-out risk and motivation to study at time T1

\begin{tabular}{llc}
\hline Motivation to study & & T1 Drop-Out \\
\hline T1 External Motivation & Pearson's Correlation & $\mathbf{. 2 7 0}$ \\
T1 Introiected Motivation & Sig. (2-tailed) & .026 \\
& Pearson's Correlation & $.246^{*}$ \\
T1 Amotivation & Sig. (2-tailed) & .043 \\
& Pearson's Correlation &. $\mathbf{3 5 3 ^ { * * }}$ \\
T1 Identified Motivation & Sig. (2-tailed) & .003 \\
& Pearson's Correlation & .008 \\
T1 Intrinsic Motivation & Sig. (2-tailed) & n.s. \\
& Pearson's Correlation & -.187 \\
\hline
\end{tabular}

As regards the second survey (cf. Table 12), there was a statistically significant positive relation between drop-out risk and Amotivation $\left(r_{66}=.545 ; p<.001\right)$. Understandably, there was a statistically significant negative relation between drop-out risk and identified motivation $\left(r_{66}=-.371\right.$; $p<.001)$ and between drop-out risk and intrinsic motivation $\left(r_{66}=-.334 ; p<.05\right)$. Hence, greater drop-out scores are correlated with higher Amotivation scores and, predictably, with lower Identified Motivation and Intrinsic Motivation scores.

Table 12. Correlations between drop-out risk and motivation to study at time T2

\begin{tabular}{llc}
\hline Motivation to study & & T2 Drop-Out \\
\hline T2 External Motivation & Pearson's Correlation & .142 \\
T2 Introiected Motivation & Sig. (2-tailed) & n.s. \\
& Pearson's Correlation & .028 \\
T2 Amotivation & Sig. (2-tailed) & n.s. \\
& Pearson's Correlation & $.545^{* *}$ \\
T2 Identified Motivation & Sig. (2-tailed) &, 000 \\
& Pearson's Correlation & $\mathbf{- . 3 7 1 ^ { * * }}$ \\
T2 Intrinsic Motivation & Sig. (2-tailed) &, 002 \\
& Pearson's Correlation & $-.334^{* *}$ \\
& Sig. (2-tailed) &, 005 \\
\hline
\end{tabular}

With regard to the third survey (cf. Table 13), there were statistically significant positive relations between drop-out risk and Amotivation $\left(r_{66}=.628 ; p<.001\right)$ and between drop-out risk and External Motivation $\left(r_{66}=.443 ; p<.001\right)$; on the other hand, there was a statistically significant negative correlation between drop-out risk and Identified Motivation $\left(r_{66}=-.491 ; p<.001\right)$ and between drop-out risk and Intrinsic Motivation ( $\left.r_{66}=-.489 ; p<.001\right)$ (see table 5). 
Table 13. Correlations between drop-out risk and motivation to study at time T3

\begin{tabular}{llc}
\hline Motivation to study & & T3 Drop-Out \\
\hline T3 External Motivation & Pearson's Correlation &. $\mathbf{4 4 3}$ \\
T3 Introiected Motivation & Sig. (2-tailed) & 000 \\
& Pearson's Correlation & .021 \\
T3 Amotivation & Sig. (2-tailed) & n.s. \\
& Pearson's Correlation & $.628^{* *}$ \\
T3 Identified Motivation & Sig. (2-tailed) & .000 \\
& Pearson's Correlation & $-.491^{* *}$ \\
T3 Intrinsic Motivation & Sig. (2-tailed) & .000 \\
& Pearson's Correlation & $-.489^{* *}$ \\
\hline
\end{tabular}

In short, the third survey also confirmed greater drop-out scores correlated to higher Amotivation and External Motivation scores and, at the same time, to lower Identified Motivation and Intrinsic Motivation scores. These correlations highlight a motivational type problem for students who develop drop-out risk linked primarily to an incoming deficit in guidance with regard to their initial choice of degree course, as is borne out by their more frequent answers to the question "Why are you attending the degree course you are enrolled in?" The following answers stand out in this regard: "I honestly don't know" and "I feel I'm wasting my time in school".

\section{Conclusions and Discussion}

In conclusion, the longitudinal data presented in this contribution confirm the existence of a strict correlation between drop-out risk and symptoms of anxiety and depression: a greater drop-out risk is significantly correlated to higher anxiety and depression scores obtained by the group of university students in a first survey (at so-called time T1). The longitudinal study showed how these very same students showed a drop-out risk strictly correlated to depression, but not to anxiety, in a third survey carried out one year later (at so-called T3). It was thus found that there was a significant decrease in anxiety scores between the first and third survey, while depression levels remained constant and high. With regard to somatization, instead, there were no significant correlations with drop-out risk across the three surveys of the study. We can thus establish that the "Depression" variable is a stable and constant dimension in the risk of student drop-out.

Finally, some correlations were made to assess the relation between drop-out risk and the cognitive strategies used by students and between drop-out risk and motivation to study for all three surveys. In short, the greater the drop-out risk, the lower the scores obtained by students with regard to Cognitive Strategies of Knowledge Practice and Knowledge Monitoring: this relation was confirmed in the two final surveys. With regard to motivation to study, it was seen how at time T1, greater drop-out scores correlated with higher Amotivation scores and, predictably, with lower Identified Motivation and Intrinsic Motivation scores. In sum, at the end of the three surveys, i.e. one year after the start of the longitudinal study, we confirmed that greater drop-out scores correlate with higher Amotivation and External Motivation scores and, at the same time, with lower Identified Motivation and Intrinsic Motivation scores. In conclusion, drop-out risk is particularly correlated to high levels of depression (distress), on the one hand, and to poor skills with regard to Cognitive Strategies of Knowledge Practice and Knowledge Monitoring and to high levels of Amotivation and External Motivation, on the other.

At the interpretational level, we can thus state that, according to our data, the greatest difficulties encountered when starting university life are particularly due to a deficit in guidance for incoming students with evident deficits in motivation with regard to the specific study path chosen. There is also a deficit in adopting adequate cognitive strategies for self-regulated knowledge that combines with a fragile emotional state already characterized by growing levels of anxiety and depression. All this does not allow students to pursue academic success and already one year later we find how thoughts of dropping out of university build up to a situation of real risk of dropping-out. 
The student's awareness of all this probably leads to a decrease in anxiety levels - i.e. to less fear and uncertainty with regard to possible academic results - but leaves an ongoing condition of depression which introduces and attitude of resignation and of abandonment of pursuing one's goals.

In this delicate period of study there is actually much that can be done to help and support students to reduce their levels of distress, which largely generates high levels of depression. Specific actions in this regard have been implemented through such channels as university counselling and guidance services, which are crucial in giving students the opportunity to obtain emotional support and a greater awareness of their own skills and aptitudes (Buchanan, 2012; Monti, Tonetti \& Ricci Bitti, 2014; Biasi, Mallia, Menozzi \& Patrizi, 2015; Biasi, Cerutti, Mallia, Menozzi, Patrizi, \& Violani, 2017). Biasi, Patrizi, Mosca and De Vincenzo (2016) recently demonstrated the effectiveness of a university counselling service for 66 students who made use of it (the experimental group), who showed lower psychological distress, including anxiety and depression, at the end of the intervention compared to a control group of 44 students on a waiting list who, for organisational reasons, could make use of the service only in the following semester. Positive effects were also recorded with regard to recovering their academic study path for the experimental group compared to the control group.

Particularly effective within the university services provided to students was the University Counseling Service for Ongoing Guidance, conducted through specific guidance interviews (Biasi, Patrizi, De Vincenzo \& Mosca, 2017) in order to favour an actual recovery of study paths. In this case, 80 students took part in these guidance interviews (the experimental group) and achieved a statistically significant resumption of their study paths at the end of the intervention compared to a control group of 52 students who were on a waiting list to use the same service during the following semester. These counselling actions are effective when they focus on both emotional support and re-guidance processes geared to real individual motivation and to the development of more effective cognitive strategies for their studies.

On the basis of the evidence obtained thus far, we deem it useful to approach incoming student guidance more systematically in order to face the possible risk of future drop-out. This can be done by establishing contacts with high schools and especially by creating specific interventions within ongoing university guidance services that can act simultaneously to improve levels of wellbeing through emotional support, to redefine choices of study paths in line with personal motivation and the gaining of awareness in this regard also through forms of empowerment in order to strengthen the perception of self-efficacy, and to develop adequate cognitive strategies and selfregulated knowledge by devising a functional study method.

\section{Acknowledgement}

This article is the result of the joint work of the three authors, in particular paragraph 2.3 (with the related subparagraphs) and paragraph 3 were written by $\mathrm{V}$. Biasi; paragraph 1 has been written by N. Patrizi and paragraphs 2.1 and 2.2. from C. De Vincenzo.

\section{References}

Achenbach, T. M., \& Rescorla, L. A. (2003). Manual for the ASEBA adult forms \& profiles. Burlington, VT, USA: Research Center for Children, Youth, \& Families, University of Vermont.

Achenbach, T. M., Dumenci, L., \& Rescorla, L. A. (2003). DSM-oriented and empirically based approaches to constructing scales from the same item pools. Journal of Clinical Child and Adolescent Psychology, 32(3), 328-340.

Achenbach, T. M., Bernstein, A., \& Dumenci, L. (2005). DSM-oriented scales and statistically based syndromes for ages 18 to 59: Linking taxonomic paradigms to facilitate multitaxonomic approaches. Journal of Personality Assessment, 84(1), 49-63.

Alivernini, F., \& Lucidi, F. (2008). The Academic Motivation Scale (AMS): Factorial structure, invariance and validity in the Italian context. Testing, Psychometrics, Methodology in Applied Psychology, 15(4), 211-220. 
Alivernini, F., Manganelli, S., Cavicchiolo, E., Girelli, L., Biasi, V., \& Lucidi, F. (2017). Immigrant background and gender differences in primary students' motivations toward studying. The Journal of Educational Research (www.tandfonline.com/loi/vjer20)

Ballarino, G. (2011). Le politiche per l'università. In U. Ascoli (Ed.), Il welfare in Italia (pp.197-224). Bologna: il Mulino.

Biasi, V., Cerutti, R., Mallia, L., Menozzi, F., Patrizi, N., \& Violani, C. (2017). (Mal)Adaptive Psychological Functioning of Students Utilizing University Counseling Services. Frontiers in Psychology, Front. Psychol., 15 March | https://doi.org/10.3389/fpsyg.2017.00403

Biasi, V., De Vincenzo C., \& Patrizi, N. (2017). Relazioni tra autoregolazione dell'apprendimento, motivazioni e successo accademico degli studenti. Identificazione di fattori predittivi del rischio di drop-out. Giornale Italiano di Ricerca Didattica / Italian Journal of Educational Research, 18, 181-198.

Biasi, V., Mallia, L., Menozzi, F., \& Patrizi, N. (2015). Adaptive functioning and behavioral, emotional and social problems of Italian university students: Indications for the University Counseling Services. Procedia Social and Behavioral Sciences, 205, 66 - 69.

Biasi, V., Patrizi, N., De Vincenzo C., \& Mosca, M. (2017). I colloqui di orientamento per facilitare il successo accademico: una indagine sperimentale. Journal of Educational, Cultural and Psychological Studies, 15, 215-228.

Biasi, V., Patrizi, N., Mosca, M., \& De Vincenzo, C. (2016). The effectiveness of university counselling for improving academic outcomes and wellbeing. British Journal of Guidance \& Counselling, 1-10.

Buchanan, J. L. (2012). Prevention of depression in the college student population: a review of the literature. Archives of Psychiatric Nursing, 26(1), 21-42.

Bukhari, S. R., \& Saba, F. (2017). Depression, anxiety and stress as negative predictors of life satisfaction in university students. Rawal Medical Journal, 42(2), 255-257.

Burgalassi M., Biasi V., Capobianco R., \& Moretti G. (2016). II fenomeno dell'abbandono universitario precoce. Uno studio di caso sui corsi di laurea del Dipartimento di Scienze della Formazione dell'Università "Roma Tre". Italian Journal of Educational Research, 17, 105-126.

CNVSU (2011). XI Rapporto sullo Stato del Sistema Universitario Italiano a cura del Comitato Nazionale per la Valutazione del Sistema Universitario.

Davies, E. B., Morriss, R., \& Glazebrook, C. (2014). Computer-delivered and web-based interventions to improve depression, anxiety, and psychological well-being of university students: a systematic review and meta-analysis. Journal of medical Internet research, 16(5).

De Marco, B., \& Albanese, O. (2009). Le competenze autoregolative dell'attività di studio in comunità virtuali. Querty-Open and Interdisciplinary Journal of Technology, Culture and Education, 4(2), 123-139.

Diseth, A., \& Kobbeltvedt, T. (2010). A mediation analysis of achievement motives, goals, learning strategies, and academic achievement. British Journal of Educational Psychology, 80(4), 671-687.

Domenici, G. (2016). Istruzione, ricerca e cultura: si riparte da queste per una nuova Rinascenza? (Education, Research and Culture: Does a New Rebirth Start from These Elements?). Journal of Educational, Cultural and Psychological Studies, 13, 11-21.

Domenici, G. (2017). (Ed.). Successo formativo, Inclusione e Coesione Sociale: Strategie Innovative. Volume Primo e Volume Secondo. Roma: Armando.

Farrer, L., Gulliver, A., Chan, J. K., Batterham, P. J., Reynolds, J., Calear, A., \& Griffiths, K. M. (2013). Technology-based interventions for mental health in tertiary students: systematic review. Journal of medical Internet research, 15(5).

Geisner, I. M., Mallett, K., \& Kilmer, J. R. (2012). An examination of depressive symptoms and drinking patterns in first year college students. Issues in mental health nursing, 33(5), 280-287.

Hardre, P. L., \& Reeve J. (2003). A motivational model of rural students' intentions to persist in, versus drop out of, high school. Journal of educational psychology, 95(2), 347.

Heikkila, A., Niemivirta, M., Nieminen, J., \& Lonka, K. (2011). Interrelations among university students' approaches to learning, regulation of learning, and cognitive and attributional strategies: a person oriented approach. Higher Education, 61, 513-529.

Hysenbegasi, A., Hass, S. L., \& Rowland, C. R. (2005). The impact of depression on the academic productivity of university students. Journal of Mental Health Policy and Economics, 8(3), 145.

Hunt, J., \& Eisenberg, D. (2010). Mental health problems and help-seeking behavior among college students. Journal of Adolescent Health, 46(1), 3-10.

Ibrahim, A. K., Kelly, S. J., Adams, C. E., \& Glazebrook, C. (2013). A systematic review of studies of depression prevalence in university students. Journal of psychiatric research, 47(3), 391-400.

Lambert, M. J., \& Hill, C. E. (1994). Assessing psychotherapy outcomes and processes. In A. E. Bergin \& S. L. Garfield (Eds.), Handbook of psychotherapy and behavior change (pp. 72-113). New York: John Wiley.

Lo Coco, G., Chiappelli, M., Bensi, L., Gullo, S., Prestano, C., \& Lambert, M. J. (2008). The factorial structure of the outcome questionnaire-45: A study with an Italian sample. Clinical Psychology and Psychotherapy, 15(6), 418-423. 
Lombardo, C., Mallia, L., Battagliese, G., Grano, C., \& Violani, C. (2013). Perfectionism mediates the relationship between insomnia and depressive symptoms. Sleep and Biological Rhythms, 11(2), 90-98.

Manganelli S., Alivernini F., Mallia L., \& Biasi V. (2015). The development and psychometric properties of the "Self-Regulates Knowledge Scale - University" (SRKS-U) / Sviluppo e proprietà psicometriche della "Scala di Auto-Regolazione degli Apprendimenti - Università" (SARA-U). Journal of Educational, Cultural and Psychological Studies, 12, 235-254.

Monti, F., Tonetti, L., \& Ricci Bitti, P. E. (2014). Comparison of cognitive-behavioural therapy and psychodynamic therapy in the treatment of anxiety among university students: an effectiveness study. British Journal of Guidance \& Counselling, 42(3), 233-244.

Murai, H., \& Nakayama, T. (2008). A one-year follow-up study on predictors of temporary leaves and drop-outs among students at a women's junior college. Journal of epidemiology, 18(1), 26-36.

OECD (2010). Highlights from Education at a Glance. Paris: OECD.

Pintrich, P. R. (2004). A conceptual framework for assessing motivation and self-regulated learning in college students. Educational psychology review, 16(4), 385-407.

Pritchard, M. E., \& Wilson, G. S. (2003). Using emotional and social factors to predict student success. Journal of college student development, 44(1), 18-28.

Richardson, M., Abraham, C., \& Bond, R. (2012). Psychological correlates of university students' academic performance: a systematic review and meta-analysis. Psychological Bulletin, 138(2), 353-387.

Russell, G., \& Shaw, S. (2009). A study to investigate the prevalence of social anxiety in a sample of higher education students in the United Kingdom. Journal of Mental Health, 18(3), 198-206.

Stallman, H. M. (2010). Psychological distress in university students: A comparison with general population data. Australian Psychologist, 45(4), 249-257.

Storrie, K., Ahern, K., \& Tuckett, A. (2010). A systematic review: students with mental health problems-a growing problem. International journal of nursing practice, 16(1), 1-6.

Vallerand R. J., Pelletier L. G., Blais M. R., Briere N. M., Senecal C., \& Vallieres, E. F. (1992). The Academic Motivation Scale: A measure of intrinsic, extrinsic, and amotivation in education. Educational and psychological measurement, 52(4), 1003-1017.

Vallerand R. J., Pelletier L. G., Blais M. R., Briere N. M., Senecal C., \& Vallieres E. F. (1993). On the assessment of intrinsic, extrinsic and amotivation in education: Evidence of concurrent and construct validity of the Academic Motivation Scale. Educational and Psychological Measurement, 53, 159-172.

Vallerand R. J., Fortier M. S., \& Guay F. (1997). Self-determination and persistence in a real-life setting: Toward a motivational model of high-school drop out. Journal of Personality and Social Psychology, 72, 11611176.

Vermunt, J. D. (1998). The regulation of constructive learning processes. British Journal of Educational Psychology, 68(2), 149-171. 